\title{
La política y legislación forestal nicaragüense: implicaciones para el fomento y aprovechamiento arbóreo en fincas ganaderas*
}

Yuri Marín ${ }^{1}$, Guillermo Defeltsen ${ }^{2}$, Milton Fernández $^{3}$, Amilcar Aguilar $^{4}$ y Roberto Rivas ${ }^{5}$

${ }^{1}$ Investigador del Instituto de Investigación y Desarrollo Nitlapán, Universidad Centroamericana. E-mail: iatanitla@ns.uca.edu.ni

${ }^{2}$ Investigador del Departamento de Agroforesteria Tropical de CATIE.

${ }^{3}$ Asesor en Gestión Ambiental, Servicio Holandés de Cooperación al Desarrollo (SNV), Nicaragua.

${ }^{4}$ Coordinador del Proyecto CATIE-Noruega (PD) en Nicaragua

${ }^{5}$ Investigador del Instituto de Investigación y Desarrollo Nitlapán, Universidad Centroamericana. E-mail: roberto.rivas@nitlapan.org.ni

Recibido: junio de 2007 / Aceptado: julio de 2007

ESTE ESTUDIO VINCULA LA PROBLEMÁTICA FORESTAL Y AMBIENTAL A NIVEL MICRO con el nivel de políticas más sectorial a través de un estudio de caso y consulta a expertos locales y nacionales. Aporta al conocimiento de las principales barreras legales e institucionales que impiden a los finqueros ganaderos fomentar y aprovechar mejor el recurso arbóreo en sus fincas. Identifica medidas de políticas y ajustes al marco legal forestal que podrían contribuir a favorecerlo. El estudio discute sobre el desconocimiento de la legislación forestal del país entre los finqueros y una falta de coordinación entre los actores institucionales, INAFOR y alcaldías, en relación con la gestión del recurso y el otorgamiento de permisos para aprovechamiento, lo que favorece la ilegalidad y la no sostenibilidad de los recursos forestales. Se concluye que en zonas ganaderas del interior existe un potencial de aprovechamiento forestal que puede ser explotado de manera sostenible si se dirige la atención a mejorar los conocimientos del marco regulatorio, la capacidad de manejo técnico del recurso arbóreo en fincas, el entrenamiento en el manejo de la legislación y los procedimientos para el aprovechamiento forestal, y la articulación entre el INAFOR y las municipalidades en un marco de descentralización.

Palabras clave: política forestal-Nicaragua / bosques-legislación / ganadería

\section{Introducción}

A pesar de su importancia social y económica, la ganadería en América Central ha sido considerada como una actividad dañina para el medio ambiente. A los ganaderos centroamericanos con frecuencia se les acusa de estar entre los principales causantes, a nivel regional, del proceso de deforestación, degradación de suelos y contaminación 
ambiental. Por otra parte, cerca de la mitad de las nueve millones de hectáreas de pasturas existentes en América Central están degradadas (Szott et al., 2000).

En Nicaragua, el avance de la frontera agrícola y su relación con la ganadería extensiva han sido fuertemente asociados a la pérdida de cobertura arbórea y de capital natural en general, situación que ha determinado la limitación de opciones de diversificación, intensificación y adopción de buenas prácticas productivas en estas áreas.

Varios estudios realizados por el CATIE (Centro Agronómico Tropical de Investigación y Enseñanza), el CIPAV (Centro de Investigación en Sistemas Sostenibles de Producción Agropecuaria) y otras instituciones, han generado información útil sobre alternativas sostenibles de intensificación ganadera que permitirían rehabilitar importantes áreas con pasturas degradadas. Entre otras prácticas, el manejo de bosques secundarios y plantaciones arbóreas o la regeneración natural de árboles en potreros de fincas ganaderas se perfilan como alternativas para sistemas de pastoreo de ganado que diversifiquen el uso de la tierra, y mejoren la productividad y los ingresos ganaderos, logrando reducir la deforestación, degradación ambiental y pobreza en las áreas productoras de ganado.

Aunque existen tecnologías y prácticas silvopastoriles que puedan hacer más viable biológica, económica y sosteniblemente el manejo de la ganadería en Nicaragua, uno de los principales obstáculos que encuentran los productores ganaderos para fomentar y aprovechar el componente arbóreo en sus fincas es la falta de políticas y legislación forestal adecuada para fomentar el uso sostenible de las tierras ganaderas en zonas del trópico húmedo y subhúmedo.

Sin embargo, muy poco se ha vinculado la problemática forestal y las necesidades de los finqueros a nivel micro, con el nivel de políticas más sectoriales o macro. Existe la presunción de que un mayor fomento y mejor aprovechamiento forestal dirigido a los miles de propietarios de fincas agropecuarias podría disminuir la presión sobre el bosque y aumentaría significativamente la cobertura forestal del país. Este trabajo tiene como propósito aportar al conocimiento acerca de las principales barreras legales e institucionales que impiden a los finqueros ganaderos desarrollar y hacer un mayor aprovechamiento del recurso arbóreo en sus fincas y señalar cuáles medidas de políticas y ajustes al marco legal forestal podrían contribuir a favorecerlo.

\section{Metodología}

El estudio se realizó en el municipio de Muy Muy, ubicado entre los $85^{\circ} 45^{\prime}-85^{\circ} 30^{\prime}$ de longitud oeste y $12^{\circ} 50^{\prime}-12^{\circ} 40^{\prime}$ de latitud norte (ver Ilustración 1). 


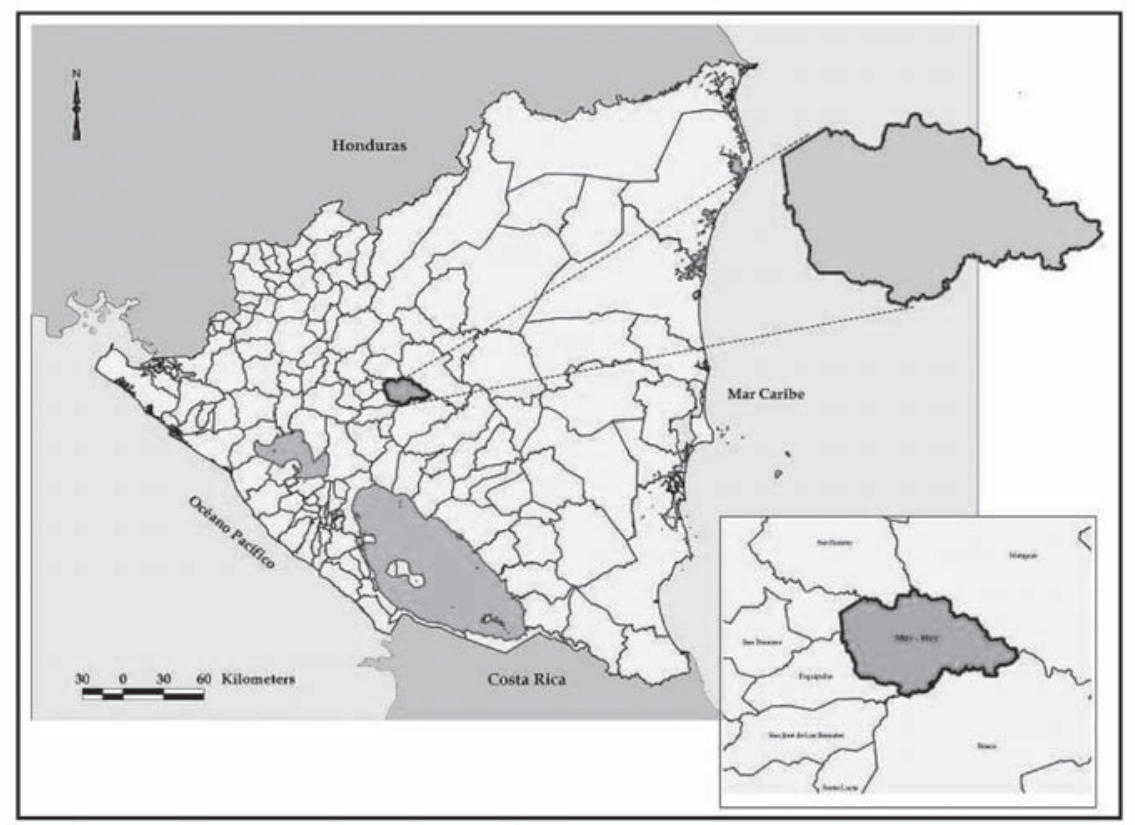

Ilustración 1. Localización de Muy Muy

El ecosistema es de trópico semihúmedo con precipitaciones entre 1500 a $1700 \mathrm{~mm}$ anuales y un verano marcado (diciembre-abril). La altura predominante oscila entre 200 y $400 \mathrm{~m}$. Los suelos son frágiles; la topografía presenta 32\% de terrenos planos, 41\% ondulados y 27\% quebrados (Esquivel, 2005). La mayor parte de la superficie (53\%) está cubierta de pastos y presenta evidentes síntomas de degradación. La cobertura de bosques es inferior al 5\%, pero en algunas áreas se puede observar un importante proceso de regeneración natural en potreros, lo que es indicador del potencial forestal de algunas zonas ganaderas. Esto permite aseverar que estos renovales pueden representar una oportunidad de diversificación de ingresos aunada a mejorar la gestión ambiental de las fincas ganaderas.

El territorio es atravesado por una carretera pavimentada que permite la integración con los mercados de lácteos y carne. Los productores son en su mayoría (891) pequeños y medianos (30-70 Ha), orientados a la producción de doble propósito con énfasis en leche (INEC, 2002).

\subsection{Procedimientos metodológicos utilizados}

Para efectos del estudio se recurrió a tres fuentes de información: el marco legislativo forestal, la opinión directa de los productores y otros actores locales, y la revisión de información secundaria y estadísticas sectoriales. Primeramente se realizó una revisión del estado de las políticas y del marco jurídico forestal vigente en el país y otras leyes relacionadas.

También se revisaron los resultados de la Modelación de Presiones sobre la Biodiversidad (CCAD et al., 2006) en función de analizar por qué pueden ser interesantes los desarrollos forestales en pequeñas y medianas fincas ganaderas. 
Los hallazgos principales de la investigación documental fueron combinados con sondeos de opinión a diferentes actores locales. Esta técnica se aplicó a una docena de productores ganaderos y cuatro instituciones gubernamentales y no gubernamentales presentes en el municipio de Muy Muy (INAFOR, Alcaldía Municipal, FONDEAGRO y ODESAR). Se demandó información sobre los siguientes aspectos: a) la influencia de la legislación en las decisiones de manejo arbóreo; b) las iniciativas de fomento del aprovechamiento forestal, regeneración natural y/o establecimiento de plantaciones; c) los mecanismos que debería propiciar el Estado para masificar el aprovechamiento arbóreo; y sobre el municipio: d) el potencial existente para el aprovechamiento forestal.

Finalmente, los resultados del análisis del marco legislativo forestal y del sondeo se contrastaron y validaron con dos grupos focales, uno local y otro nacional. El primero se conformó a nivel municipal con la participación de ganaderos, muebleros, representantes de la Alcaldía y Policía, ONG, delegados del MAGFOR, FONDEAGRO e INAFOR y el CATIE. Para el segundo grupo se realizó un taller nacional con la participación de actores de las organizaciones rectoras en materia sectorial y subsectorial, actores de la sociedad civil, proyectos del Estado relacionados y universidades.

\section{Resultados y discusión}

\subsection{La política forestal y sus limitaciones}

En el objetivo general de la Política de Desarrollo Forestal de Nicaragua (Decreto 50- 2001) se estipula: "Lograr el desarrollo sostenible del sector forestal, constituyéndose en una alternativa viable para elevar la calidad de vida de la población ligada al recurso y en un eje de desarrollo para la economía nacional" (Arto.3), pero en la realidad esto está todavía lejos de alcanzarse. Con la creación de las áreas protegidas se disminuyó la destrucción de ciertas áreas de interés nacional, pero la problemática forestal del país sigue latente y la política actual contiene vacíos de enfoque (Faurby, 2005).

Varios autores coinciden en señalar que las políticas forestales de años anteriores han sido, por lo general, restrictivas y poco efectivas para lograr el desarrollo del sector; redundando en efectos contrarios a los esperados para: a) aumentar la cobertura forestal del país, b) incrementar las exportaciones de madera procesada y c) mantener precios accesibles - de la madera - a la población.

De acuerdo con Segura (1997), las políticas forestales han tendido a ser relegadas a políticas sectoriales con poca visión integral sobre su papel en el desarrollo económico y social del país. Para Barahona (1997), las políticas aplicadas en el pasado no han sido muy efectivas ni para frenar la destrucción del bosque, ni para incentivar a la industria forestal a generar divisas para el país. Existe más bien una tendencia hacia la tala ilegal y el contrabando de madera. El sesgo prohibitivo de las políticas forestales ha provocado que amplios segmentos del mercado de la madera y de la leña se desarrollen en la ilegalidad.

Para Faurby (2005), la política forestal de las últimas dos décadas se ha construido sobre una serie de supuestos incorrectos sobre la realidad del país. Entre otros, que: 
- la madera y la leña son recursos escasos

- la actividad maderera es la amenaza principal para el bosque

- las plantaciones son una solución a los problemas ambientales y a la escasez de madera y leña

- los pequeños y medianos productores agropecuarios son irrelevantes en la producción forestal

Varios autores reconocen que, ni la actividad maderera ha sido la principal responsable de talar el bosque, ni las plantaciones han demostrado ser el método más barato para aportar leña y madera, y resolver algunos problemas ambientales críticos para la sociedad.

Por otro lado, la leña que se consume en el país y gran parte de la madera que se procesa en los aserraderos proviene de fincas agropecuarias, incluyendo árboles en potreros. De hecho, amplias zonas rurales del país, aproximadamente 4 millones de hectáreas, están bajo sistemas de agroforestería y/o ganadería con importante presencia de árboles en potreros (MAGFOR et al., 2002). Con tal cantidad de recursos forestales en manos de los pequeños y medianos productores del país, en vez de hablar de escasez de madera y leña, ${ }^{1}$ deberíamos de preguntarnos cuáles son los fenómenos y procesos que inciden en su "escasez" y su bajo nivel de aprovechamiento.

Una pista proviene del hecho que las legislaciones y políticas forestales de Nicaragua no han considerado que casi todos los dueños de bosques sean también productores agropecuarios. Por esta razón, históricamente y en la actualidad, la política forestal no ha fomentado la actividad como un componente atractivo dentro de la finca. En contraposición a la idea de ciertos expertos, la realidad es que el peso de esta política descansa más en la conservación de los bosques, quedando el aprovechamiento y fomento prácticamente subordinado a ello y no a un uso racional del recurso. Por ende, las estrategias de comando y control se privilegian más que el fomento de la propia producción y la política se vuelve cada vez más restrictiva (Faurby, 2005; Larson, 2006). La nueva "Ley de Veda Forestal" (Ley 585-2006) viene a reforzar dicho carácter restrictivo, contradiciendo los mismos objetivos del Fondo Nacional de Desarrollo Forestal (FONADEFO). Sin embargo, como se abordará adelante, la legislación forestal actual y su reglamento contienen algunas "ventanas" que posibilitan fomentar un manejo sostenible de los recursos arbóreos existentes en las fincas.

Otra pista proviene del nivel municipal: el bosque y los árboles en fincas que ofrecen bienes y servicios ambientales a la población no han sido considerados como parte de una agenda seria de desarrollo sostenible (Larson, 2006). Las preocupaciones en "lo forestal" se han encasillado en la reforestación o quizás en la conservación de áreas protegidas a nivel local.

\section{2. ¿Por qué es importante impulsar desarrollos silvícolas en fincas ganaderas?}

Para este análisis se debe de tener presente la siguiente pregunta: ¿́por qué pueden ser valiosos algunos desarrollos diversificados de fincas ganaderas en lo forestal, si no son primariamente enfocados hacia este sector? Un elemento central a tomar en cuenta es partir de la consideración de los siguientes aspectos: 
1. La ganadería ha jugado un papel importante en el avance de la frontera agrícola.

2. Las prácticas extensivas han deteriorado los ecosistemas, bajando la productividad.

Los resultados de la "Modelación de Presiones sobre la Biodiversidad" (CCAD et al., 2006) dan cuenta de la pérdida de cobertura vegetal en el país respecto al ecosistema que originalmente existió. ${ }^{2}$ Esta evaluación tiene como base el mapa de eco regiones de 1995 (FAO), contrastado y corregido con el de usos del suelo de 2000 (Ilustración 2). El resultado es una fuerte tendencia a la pérdida de riqueza en biodiversidad y opciones de desarrollos diversificados en el área rural.

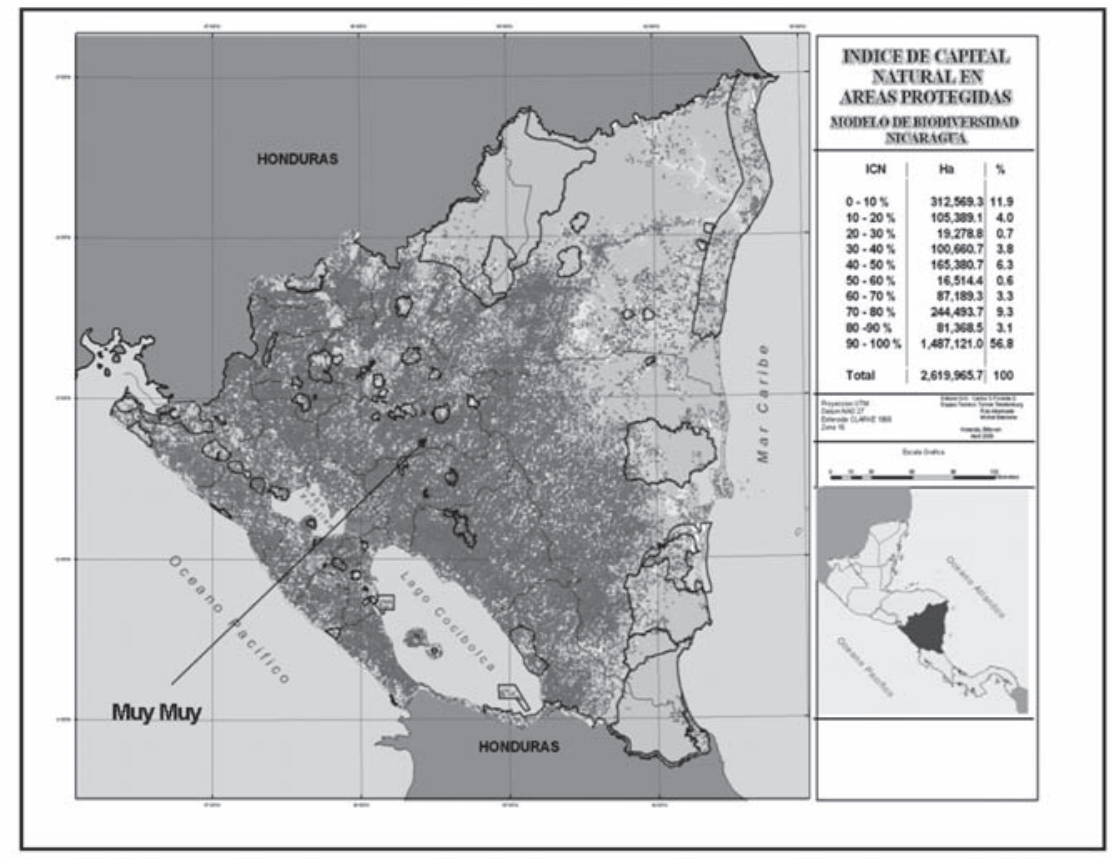

Clave: Rojo de 0 a10\% de capital natural original; Verde de 90 a 100\% de capital natural original.

Fuente: CCAD et al., 2006.

Ilustración 2. Capital natural original de Nicaragua.

A pesar de ello se evidencia Muy Muy como un municipio que, por sus actuales características ecosistémicas - pendiente y suelos -, presenta un alto potencial para desarrollos silvoagropecuarios (un 50\%, aproximadamente unas 18,370 has), con eventuales impactos en el nivel de vida de las familias rurales si estos potenciales fueran bien aprovechados (Van Der Zee $e t a l ., 2007)$. Prueba de ello es que en la actualidad existen en Muy Muy renovales naturales (manchones de recuperación natural) sin asistencia ni manejo. Éstos pueden representar opciones de diversificación productiva en fincas, contribución al incremento del capital natural y la rehabilitación de ecosistemas, y conectividad del paisaje. Esto es apreciable en otros municipios de la llamada "Cuenca lechera", como Río Blanco, Matiguás, Esquipulas y otros principalmente de los departamentos de Matagalpa, Jinotega y Boaco, en los que existe un importante componente ganadero. 


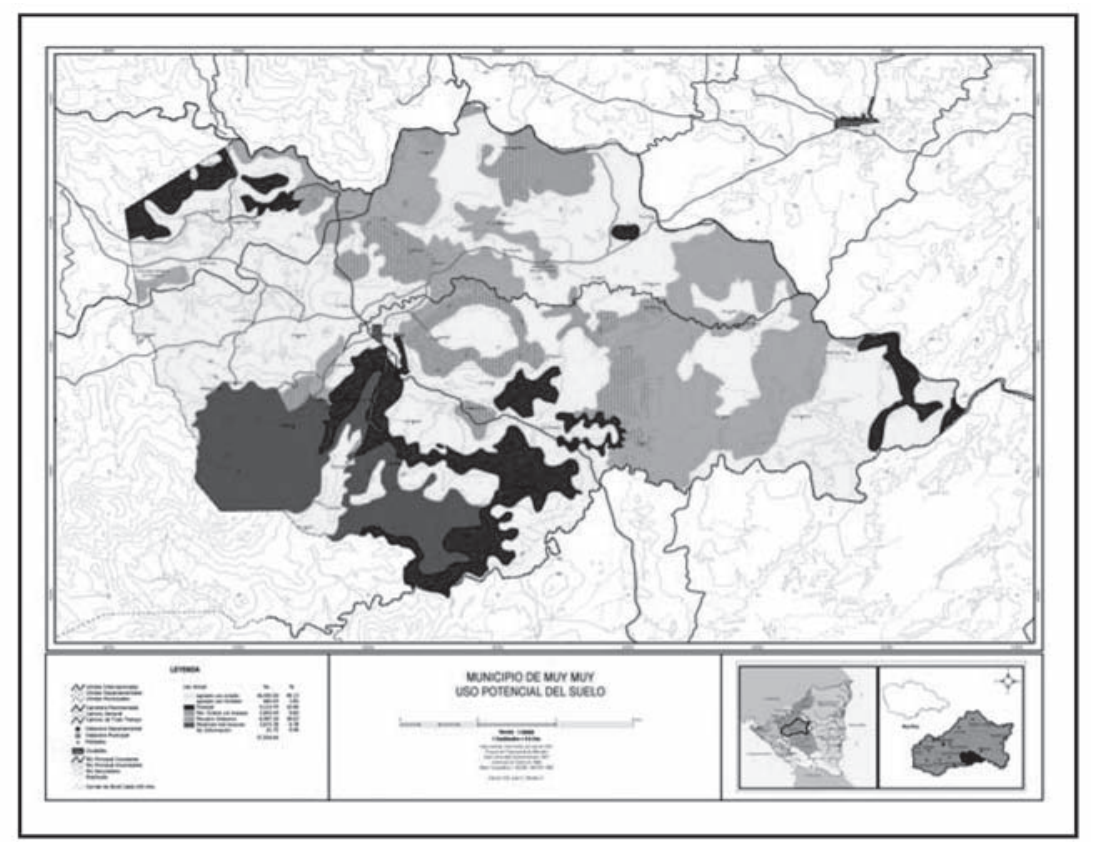

Fuente: Van Der Zee et al., 2007

Ilustración 3. Potencial de uso de la tierra del municipio de Muy Muy.

\subsection{El marco jurídico general y particular que rige al sector forestal}

El marco jurídico vinculante al sector forestal en Nicaragua parte de la Constitución de la República y de las leyes que rigen en materia de legislación orgánica sectorial, ambiental y de participación ciudadana en el país. Se concretiza con otras leyes y decretos listados en el Anexo 1.

Las instituciones estatales más importantes en la gestión de los recursos forestales en el país son: el Instituto Nacional Forestal (INAFOR), órgano rector de la gestión forestal, adscrito al MAGFOR con el papel de "velar por el cumplimiento del régimen forestal en todo el territorio nacional"; el Ministerio del Ambiente y los Recursos Naturales (MARENA), encargado de los asuntos ambientales y la administración de las áreas protegidas; adicionalmente se ha creado el Fondo Nacional de Desarrollo Forestal (FONADEFO), del cual se esperan funciones como un mecanismo fiduciario de incentivo al desarrollo forestal; también son importantes el Ministerio de Fomento y Comercio (MIFIC), que se encarga de las concesiones forestales otorgadas por el Estado; y el Ministerio de Hacienda y Crédito Publico (MHCP), encargado de la recaudación fiscal en el país y de las transferencias presupuestarias municipales (Serrato, 2002).

Este marco legal es, en general, poco conocido por la población, los gobiernos locales y usuarios/as locales de los recursos forestales. Este elemento, aunado a una "mala historia" de la ganadería en materia forestal y a una extendida visión conservacionista en materia ambiental de actores sectoriales y la sociedad civil, determina una visión y un 
escenario conservadores respecto al aprovechamiento y desarrollos forestales en contextos ganaderos.

\subsubsection{Análisis de las normativas generales que regulan la gestión y aprovechamiento de los recursos naturales en Nicaragua}

Existe una serie de políticas nacionales y normativas generales en las cuales se reconoce claramente la importancia ecológica, social y económica de los recursos naturales en el país - incluyendo los recursos forestales -, y el rol que debe jugar el Estado, sus instituciones, las municipalidades y la ciudadanía, en la regulación de su aprovechamiento y conservación. A continuación se analizan las normativas generales más importantes.

En primer lugar, el marco legal estipula claramente que los recursos naturales son parte del patrimonio nacional y señala al Estado como responsable de otorgar el derecho de aprovechamiento mediante concesiones, permisos, licencias o cuotas (Constitución de la República). Se estipula que el Estado puede establecer y ejecutar una política de incentivos y beneficios económicos a quienes contribuyan, a través de sus inversiones, a la protección, mejoramiento y restauración del ambiente.

Aunque las Leyes 462 y 290 limiten el poder de los municipios en permisos y concesiones a una simple opinión, en la realidad la carga de los incentivos económicos descansa fundamentalmente en las alcaldías. Esta situación les genera contrariedades, ya que la consideran una expropiación de sus recursos. Sucede que muchas alcaldías localizadas en territorios ambientalmente degradados operan con bajo presupuesto. De esta forma se moldea un contexto que incentiva "por defecto" un abandono relativo del tema de fomento de algunas actividades forestales en aquellas fincas ganaderas con potencial de generación de ingresos y ahorros a partir de la diversificación productiva.

Por otro lado, la Ley 462 obliga a elaborar estudios de impacto ambiental para el aprovechamiento de recursos forestales con extensiones mayores de 500 Ha. Aunque en general la aplicación de esta norma es positiva, los costos financieros para ciertas comunidades indígenas o dueños de bosque con menos capacidad económica, se pueden constituir en una barrera que provoca un aprovechamiento clandestino del bosque.

Los gobiernos municipales tienen competencia en todas las materias que incidan en el desarrollo socioeconómico y conservación del ambiente y los recursos naturales de su territorio. También es mandato de los municipios el desarrollo del ordenamiento de su territorio a través del Sistema de Planificación Municipal. Sin embargo, las concesiones forestales dependen del MIFIC (Adforest), lo que genera un conflicto de competencias que no favorece un manejo forestal coherente y armónico.

En su nuevo esquema de planificación de inversiones, el FISE introduce una condición de competitividad municipal basada en recaudaciones. A esto hay que agregar una cierta tendencia de los gobiernos locales a considerar las "mejoras" forestales como un incremento de capital en la finca, lo que se traduce en incremento en el Impuesto sobre Bienes Inmuebles (IBI) para finqueros /as que buscan mejorar la cobertura arbórea en sus tierras. 
Eventualmente, existen ordenanzas municipales que exoneran el IBI a estos desarrollos, pero no es la "moda" nacional. Estos dos fenómenos conducen a presiones contradictorias en los gobiernos locales en relación a la inversión de recursos en la facilitación de un clima de negocios favorable al sector forestal y revelan la importancia de desarrollar una política fiscal local más clara.

Sin embargo, a pesar de que los municipios tienen por ley algunos espacios de participación para promover una gestión sostenible de sus recursos forestales, en la práctica no controlan los beneficios económicos que se derivan de ellos. Prueba de ello es que la Ley Forestal y su Reglamento, otorgan al INAFOR el control exclusivo y casi absoluto en temas relativos a la producción y el ingreso proveniente del aprovechamiento forestal.

Este escenario desincentiva a los gobiernos locales y otros actores municipales a tener una visión articulada en el sector forestal que se traduzca no sólo en desarrollos industriales vía plantaciones, sino en manejos y desarrollos locales y comunitarios con fines comerciales y con enfoque de sostentabilidad ambiental.

El marco legal también refuerza las instancias y mecanismos de participación establecidos en la Ley de Municipios. Por ejemplo, estipula mecanismos para que los ciudadanos promuevan iniciativas de resolución y ordenanzas, y exige que se realicen consultas sobre asuntos de importancia en los municipios tales como la gestión y protección de los recursos naturales. De acuerdo a Larson (2006), esta Ley puede ayudar a mejorar la rendición de cuentas por parte del gobierno a todos los niveles siempre y cuando la creación de nuevas instancias de concertación no diluya la participación efectiva de la población.

La Ley Forestal o Ley 462 de 2003 y su Reglamento (Decreto 73-2003) fue creada con el objeto de "establecer el régimen legal para la conservación, fomento y desarrollo sostenible del sector tomando como base fundamental el manejo del bosque natural, el fomento de las plantaciones, la protección, conservación y la restauración de áreas forestales" (Arto. 1, Ley 462). Menciona la importancia de mejorar el nivel de vida de la población mediante la gestión forestal y dar participación a los gobiernos regionales y municipales y a la sociedad civil para velar por la conservación del recurso, asegurando los múltiples beneficios en bienes y servicios producidos por los bosques. También establece que el INAFOR desarrollará sus actividades en el territorio a través de distritos forestales desconcentrados en los cuales deberán participar representantes de las siguientes instituciones, según corresponde: 1) INAFOR; 2) Alcaldías; 3) Consejos Regionales; 4) Universidades (donde existan); 5) Policía Nacional; 6) Ejército Nacional; 7) Ministerio de Educación; 8) MARENA; y 9) Representante de Asociaciones Forestales. Establece además, que todas las actividades mencionadas en los incisos anteriores del presente artículo deberán ser coordinadas con las autoridades municipales.

Con respecto a la delegación de atribuciones, la Ley Forestal establece en el Arto. 10 que: los gobiernos municipales, previa aprobación de sus respectivos Concejos, podrán celebrar Convenios de Delegación de Atribuciones Forestales con el INAFOR para el otorgamiento de permisos de aprovechamiento comercial, seguimiento, vigilancia y control, mediante mecanismos que serán definidos en el Reglamento de esa Ley. Además, en el Arto. 11 
establece que los acuerdos y convenios que en materia forestal celebre INAFOR con personas naturales o jurídicas, podrán versar sobre la instrumentación de programas forestales, y el fomento a la educación, cultura, capacitación e investigación forestales, entre otros.

Ambos artículos son abiertos en cuanto a atribuciones y podrían permitir, por ejemplo, delegar en las instancias municipales partes de los procesos administrativos relacionados al manejo forestal sostenible de árboles en potreros, acercando estos trámites a los usuarios y mejorando las oportunidades de registro y recaudación compartida originada en operaciones que hoy se desarrollan en la ilegalidad. No obstante, los gobiernos municipales perciben que la Ley afecta en forma negativa sus finanzas. Con respecto al aprovechamiento, se establece en los Artículos 48 y 49 un "pago único" del 6\% del precio de la madera proveniente de explotaciones de bosques naturales, del cual solamente el 35\% se devuelve a las municipalidades. Por no estar vinculado a fondos locales (por ejemplo: fondos de servicios ambientales locales) a los municipios les resulta difícil escrutar este proceso, lo que resulta en pérdida de credibilidad en la redistribución de este impuesto recaudado. Por esto, muchos gobiernos municipales cobran algún impuesto sobre la madera extraída en su jurisdicción.

Por otro lado, y como se ha señalado, las propiedades donde hay plantaciones y las áreas con un plan de manejo forestal son exoneradas del 100\% del (IBI), una de las fuentes de ingresos más importantes para las municipalidades. Esta situación resulta en un incentivo perverso en materia social, pues al excluir a pequeños tenedores de bosque, por defecto incentiva que estos sectores usen el recursos forestal sin ningún manejo, en la ilegalidad y en general, bajo el poder de grupos madereros que esquilman al finquero/a, presionando aún más las dotaciones forestales en fincas ganaderas.

Como limitante se puede mencionar que aunque la Ley 462, en su Artículo 5, menciona a los dueños de territorios donde hay bosques como miembros de la Comisión Nacional Forestal, ${ }^{3}$ no les da mucha importancia y no hace nada para mejorar su situación. La Ley refleja principalmente la "participación" de los clientes de INAFOR y la privatización de algunos servicios, como la formulación y supervisión de los planes de manejo, a través de la regencia forestal. Los profesionales calificados para este trabajo pueden "participar en la gestión forestal” siendo regentes. Sin embargo, la "participación” también se debería de referir a la posibilidad real de los pequeños y medianos productores de participar en el sector como forestales, agroforestales, leñeros y artesanos, posibilidades esenciales para cualquier iniciativa seria sobre equidad y alivio de la pobreza (Barahona, 2002; Larson \& Zeledón, 2004).

Por otro lado, se considera que el aprovechamiento de madera que no proviene de plantaciones certificadas por INAFOR requiere de muchas gestiones y pagos adelantados de impuestos, por lo cual los campesinos pobres están prácticamente excluidos de cortar árboles por sus propios medios. En caso que deseen vender unos pocos árboles no les resulta económico viajar hasta la cabecera de su municipio para gestionar una o varias veces la inspección de INAFOR, por lo que se ven obligados a depender de la participación de un maderero o caer en ilegalidad. En este sentido, la intermediación de los madereros más los costos adicionales aumenta sus costos de transacción. Todos estos controles y los castigos que 
implican ponen a las autoridades en una posición de conflicto ante los dueños de árboles y no incentivan a mejorar la eficiencia y productividad del sector. Sin embargo, esta situación podría revertirse si el Estado descentralizara algunos procesos administrativos o parte de ellos y mejorara sus presupuestos en función de fomentar y llevar adelante procesos de desconcentración que se aproximen a la gente.

Por su parte, la Ley de Veda para el Corte, Aprovechamiento y Comercialización del Recurso Forestal (Ley 585) trata de responder a la problemática de la tala ilegal en el país y la sobreexplotación de algunas especies forestales importantes proveniente de áreas protegidas y de áreas sin planes de manejo. Aunque el espíritu de esta Ley podría ser positivo, la experiencia de la aplicación de leyes que han vedado el manejo del recurso arbóreo en otros países ha demostrado que generalmente se han constituido en verdaderos obstáculos al manejo de los recursos naturales renovables y terminan frenando el desarrollo forestal sostenible.

La Ley tiene sus aspectos positivos ya que ofrece oportunidades en los siguientes aspectos:

- Fomentar encadenamientos de la producción primaria con otros eslabones de la cadena de transformación, lo que permitiría generar un mayor valor agregado a la industria y posicionar mejor en los mercados la industria forestal con los consecuentes beneficios para los participantes.

- Aprovechamiento de especies maderables que tienen mayor dificultad en su transformación pero también buenos precios en los mercados.

- También posibilita controlar la tala ilegal, y favorecer la regeneración natural de las especies forestales sobreexplotadas y restaurar su equilibrio.

Sin embargo, la otra cara de la moneda la constituye el riesgo de que, en vez de beneficiar, pudiera afectar a muchos nicaragüenses que viven del negocio de la madera, y sobre todo a los pequeños y medianos productores. Por su parte, los grandes industriales de la madera quedan en términos generales amparados en el Arto. 3, donde se indica que no estará sujeta a la veda la madera proveniente de plantaciones debidamente inscritas en el Registro Nacional Forestal del INAFOR, así como aquella madera procesada en segunda transformación industrial siempre y cuando se haya cumplido con lo establecido en los Planes de Manejo correspondientes. De esta manera se excluye, "de jure”, a pequeños y medianos tenedores de bosque, lo que nuevamente incentiva a estos grupos sociales a realizar estas transacciones en la ilegalidad y en manos de mafias forestales. ${ }^{4}$ Los obstáculos que representa esta Ley para el aprovechamiento forestal sostenible pueden incrementar el aprovechamiento ilegal y/o encarecer los costos de la madera como materia prima y por lo tanto, encarecer los costos al consumidor final nicaragüense.

En síntesis, la nueva "Ley de Veda Forestal” parece dar marcha atrás a varios de los espacios que quedaban abiertos para contribuir a revertir la problemática forestal del país, afectando consecuentemente la posibilidad de mejorar los ingresos, en el corto y mediano plazo, de miles de pequeños productores ganaderos que han venido dejando en sus potreros algunas de esas especies que ahora no pueden aprovechar por estar en veda. 
Por su parte, la Ley Especial de Delitos contra el Medio Ambiente y los Recursos Naturales (Ley 559-2005) tiene como propósito tipificar las acciones más relevantes como delitos en contra del ambiente y los recursos naturales. En teoría podría conllevar a un mejor cuidado con respecto a restablecer la regeneración arbórea en algunas fincas. Prueba de ello lo constituyen artículos positivos para la conservación forestal como el Arto. 30, relacionado con la tala rasa, el Arto. 31, referente a tala en vertientes y pendientes, y el Arto. 40, que se relaciona a la alteración del paisaje natural.

Sin embargo, hay que reconocer que dada la debilidad institucional actual, será difícil alcanzar resultados de impacto, y restan por dilucidarse casos en los que la Ley pueda prestarse a la realización de acusaciones injustas, conflictos vecinales, gastos innecesarios e inclusive generar mala imagen al manejo sostenible de la regeneración arbórea natural en fincas ganaderas.

Finalmente, la Resolución administrativa No. 35-2004, Disposiciones para el Manejo Sostenible de los Bosques Tropicales, establece disposiciones administrativas para el manejo sostenible de los bosques naturales tropicales, latifoliados, coníferas y plantaciones forestales. Este cuerpo legal también define los requisitos y procedimientos para el aprovechamiento en fincas agrosilvopastoriles.

Una dificultad que entraña la aplicación de esta resolución es que corresponde a las delegaciones del INAFOR realizar la inspección técnica gratuita y emitir una guía de transporte simplificada sin costo alguno. Pero la debilidad de personal, presupuesto y cobertura del INAFOR dificulta estos procedimientos (Global Witness, 2007). Sin embargo, lo anterior puede resolverse mediante convenios entre el INAFOR y gobiernos locales para un manejo descentralizado que logre la simplificación de procesos e instrumentos económicos. Adicionalmente, sería conveniente promover la formación de una Norma Técnica Obligatoria (NTON) para este tipo de desarrollos forestales.

\subsection{Resultados del sondeo a productores ganaderos sobre el potencial e influencia de la legislación forestal para el aprovechamiento de recursos arbóreos en fincas ganaderas}

\subsubsection{Potencial para el aprovechamiento forestal}

De acuerdo a los 12 productores entrevistados, la mayoría tiene árboles de corta en sus fincas ganaderas. De éstos, menos de la mitad está pensando en aprovechar árboles para la venta, aunque en su mayoría los aprovecharán para usarlos en la finca.

Las especies arbóreas predominantes son cedro (Cedrela odorata), pochote (Bombacopsis quinata), guanacaste (Enterolobium cyclocarpum), coyote (Platymiscium dimorphandrum), genízaro (Samanea saman) y roble (Tabebuia rosea). Las más demandadas en el mercado son esas mismas especies que poseen abundantemente en sus fincas, más caoba (Switenia spp.) y laurel (Cordia alliodora). 
Cerca de la mitad de los productores manifestó vender la madera aprovechada en sus potreros en pie y otra cantidad similar ya aserrada. Por lo general ellos buscan al comprador, aunque con frecuencia venden la madera al comprador que se interese en sus árboles y les busque.

\subsubsection{Influencia de la legislación forestal en las decisiones del manejo arbóreo en las fincas de Muy Muy}

Aparentemente la legislación forestal no influye en el aprovechamiento de los árboles maderables en las fincas de los productores entrevistados. El resultado encontrado fue que son las normas locales establecidas por la municipalidad las que aplican los productores ganaderos de esta zona, pues el 58\% indicó conocer los requisitos establecidos para dichos aprovechamientos por la municipalidad. Más de la mitad del grupo consultado manifestó saber que hay multas y otras sanciones por el aprovechamiento de los árboles maderables sin ningún permiso, pero lo que no tienen claro es cuál institución aplica dichas multas y sanciones. Muchos piensan (60\%) que es el MARENA el encargado de la parte punitiva por parte del Estado, sin embargo, la entidad encargada es el INAFOR.

Por otro lado, solamente una cuarta parte de los productores (25\%) ha realizado aprovechamientos forestales recientemente y ninguno de ellos ha solicitado los servicios de los regentes forestales. El 50\% manifestó que la opinión pública es el principal obstáculo para el aprovechamiento de árboles maderables en sus fincas, mientras que los trámites burocráticos solamente parecen afectar a la tercera parte (33\%) de los productores entrevistados.

Estos resultados parecen indicar que el conocimiento del marco legal por parte de la población es limitado. Si a esto se le agregan los prejuicios sobre el aprovechamiento de los recursos forestales, se tiene como resultado una percepción negativa de dichos aprovechamientos. Los resultados también hacen entrever desconocimiento sobre la poca normativa existente y por ende, una tendencia a evitar la visita de un técnico y el permiso del INAFOR.

\subsubsection{Fomento del aprovechamiento forestal y del establecimiento de plantaciones forestales en fincas ganaderas}

Según los resultados del sondeo, el 83\% de los productores considera la producción de árboles dentro de sus potreros como un negocio, pero sólo una cuarta parte de ellos (25\%) afirma haber obtenido permisos recientes para el aprovechamiento forestal en sus fincas ganaderas y ninguno manifestó haber tramitado permisos de transporte.

Esto indicaría que la comercialización de la madera proveniente de las fincas ganaderas de Muy Muy es solamente para uso local y/o comercio ilegal (tráfico de madera y leña). Al respecto es importante considerar que existen mercados locales para madera, especialmente en el sub sector muebles. Por ende, se debería de potenciar una política y una legislación forestal que logren dar cuenta de estos mercados. Se puede tomar el ejemplo de desarrollos forestales de gran escala que han iniciado por "responder" a una necesidad local o interna para luego escalar a mercados internacionales. ${ }^{5}$ 
La regeneración natural es el método más utilizado por los productores de Muy Muy (83\%) para la repoblación forestal de sus potreros. Las fuentes y cursos de agua son, además de los potreros, otros sitios donde algunos productores (42\%) afirman establecer plantaciones forestales dentro de sus fincas. Cabe resaltar que la totalidad (100\%) de los productores entrevistados manifestó el interés de continuar la producción de árboles dentro de sus fincas ganaderas.

\subsubsection{Mecanismos que debería utilizar el Estado para la masificación del aprovechamiento de árboles maderables $u$ otros productos arbóreos en fincas ganaderas}

Se presume que las opiniones de los productores en este particular fueron muy limitadas debido al desconocimiento general de la existencia de los mecanismos que éstos pueden utilizar (por ejemplo, sólo el 33\% conoce de la existencia de los incentivos forestales).

Aunque las capacitaciones por parte del Estado constituyeron el mecanismo más sugerido (42\%) para fomentar los árboles maderables en los potreros, también se recomendó promover la publicación de la Ley No. 462 (33\%), reducir los trámites burocráticos (17\%) y gestionar nuevos proyectos con tecnologías silvopastoriles $(8 \%)$.

\subsection{Resultados del sondeo a organizaciones gubernamentales y no gubernamentales sobre el potencial e influencia de la legislación forestal para el aprovechamiento de recursos arbóreos maderables en fincas ganaderas}

\subsubsection{Potencial para el aprovechamiento forestal}

En Nicaragua aún existen grandes extensiones de tierras que cuentan con recursos forestales suficientes para el aprovechamiento de la madera, situación en la que están de acuerdo las instituciones entrevistadas (FONDEAGRO - MAGFOR, INAFOR y ODESAR).

Una de las principales limitantes para el aprovechamiento forestal, según FONDEAGRO, son los trámites que deben de realizar los productores, en los que se efectúan grandes inversiones iniciales para luego obtener pocos ingresos, lo que no hace rentable el negocio. El INAFOR justifica esa situación con la falta de conocimiento de los productores, ya que la misma Ley especifica la cantidad de días que debe de durar el proceso de aprobación de un aprovechamiento, plazo que los funcionarios de esta institución cumplen en tiempo y forma.

Las tres instituciones entrevistadas están de acuerdo en que para poder lograr las metas respecto al potencial de aprovechamiento forestal en la zona, es de gran importancia tomar en cuenta a todos los involucrados en la ejecución de la actividad forestal y dar a conocer sus funciones. También concuerdan en que sí existe el recurso maderable para ser aprovechado en esta zona, aunque se deba trabajar más con los productores en lo referente al manejo silvicultural dentro de sus fincas. 
bien establecido. En cambio, ODESAR sí observa un mercado suficientemente desarrollado en el municipio en los segmentos muebleros y madereros.

\subsubsection{Influencia de la legislación forestal en las decisiones del manejo arbóreo en las fincas ganaderas}

Para realizar esta actividad a nivel de finca, el ganadero debe solicitar por escrito al INAFOR y a los funcionarios de esta institución la ficha o guías metodológicas correspondientes para dicho aprovechamiento. La agilidad con la que se tramitará dependerá en gran medida de si el área agrosilvopastoril o bosque es mayor o menor a 10 hectáreas.

Según EL INAFOR, estos trámites no presentan dificultad alguna para que los productores płedan realizar sus aprovechamientos. Sin embargo, los representantes de ODESAR y FONDEAGRO concuerdan en que existen claras deficiencias tanto en el INAFOR como en la Alcaldía. Entre las razones por las que los productores no trabajan legalmente sus aprovechamientos forestales mencionan:

a) La lentitud de los trámites burocráticos. Ponen el ejemplo de Muy Muy, en donde la Alcaldía está a cargo de estos trámites. Allí no se cuenta con personal capacitado para la toma de decisiones y los permisos se asignan en forma discrecional.

b) La falta de educación ambiental y capacitación forestal en temas técnicos, de política y legales (tanto en productores, como en las mismas autoridades).

c) La poca coordinación entre organismos actuando sobre el territorio en temas forestales, lo que redunda en una débil visión hacia el empoderamiento de las comunidades y productores del contexto legal/ administrativo.

\subsubsection{Fomento del aprovechamiento forestal y del establecimiento de plantaciones forestales}

La Ley. No. 462 indica en el capítulo VI que "los incentivos se aplicarán a los productores que inicien o ya tengan establecidas plantaciones forestales y para el efecto tendrán que inscribir en las oficinas del INAFOR".

El representante del INAFOR considera que este incentivo no es práctico y no motiva a más productores a iniciar plantaciones. Más aún, considera que los incentivos no están generando ni nuevos empleos, ni nuevos ingresos y por ende tampoco mejoran la calidad de vida de los productores.

El representante de FONDEAGRO comparte esa opinión. Su experiencia le indica que los incentivos no son benéficos ni prácticos para aquellos productores que no cuentan con grandes extensiones de tierra para establecer plantaciones. Además indica que éste es un negocio a largo plazo y los productores no tienen capacidad de esperar muchos años para ver los beneficios del mismo, por lo cual continúan con el avance de la frontera agrícola, que es la principal causa de deforestación.

El representante de ODESAR considera que los incentivos se deberían de enfocar hacia la 
protección, y más aún en el caso de los árboles en potreros, ya que los árboles no deben de verse sólo como una fuente de ingresos sino de conservación.

Estas consideraciones deben de tomarse en cuenta para reconceptualizar los incentivos forestales hacia una dirección más equitativa. Por ejemplo, se debe atender a los pequeños y medianos tenedores de bosques quienes no son productores enfocados a desarrollos forestales. Dos razones fundamentan este considerando: primero, para llegar a desarrollos forestales industriales será necesario no sólo incentivar a grandes tenedores de bosque, sino también a grupos con potencial para un programa de transición; segundo, existen mercados locales de madera que tienen potencial de empleo y desarrollo diversificado. Estos mercados requieren de pequeños volúmenes que no son rentables para empresas forestales grandes.

Entre los mecanismos que debería de utilizar el Estado para la masificación del aprovechamiento de árboles maderables u otros productos arbóreos en fincas ganaderas, FONDEAGRO sugiere:

- Adaptar normas técnicas más favorables que incentiven el manejo.

- Trabajar más de cerca con los productores.

- Cambios en cuanto a los incentivos que motiven más a los productores a trabajar.

- Difundir a nivel nacional la nueva Ley Forestal.

- Capacitar tanto a las instituciones como a los productores en este tema.

- Promover sistemas silvopastoriles como plantaciones forestales.

\subsubsection{Consulta a expertos de nivel nacional}

En mayo de 2007 se realizó un taller nacional con diversos actores relacionados con el sector forestal. En éste se abordaron las barreras para aumentar la incorporación y el aprovechamiento de árboles en fincas ganaderas, y las estrategias para lograrlo. Se discutieron mecanismos sobre cómo:

- fomentar un programa nacional en esta línea;

- asegurar coherencia entre las leyes, reglamentos y políticas para fomentar desarrollos silvícolas en fincas ganaderas;

- fomentar una cadena de valor a partir de estos desarrollos;

- reducir la ilegalidad.

También se discutió sobre qué necesitarían las municipalidades, los regentes forestales y otros sectores para contribuir con el MAGFOR y el INAFOR al manejo sostenible de productos arbóreos en fincas ganaderas. Como barrera principal se identificó la arraigada cultura productiva (tradición ganadera). No obstante, ésta se puede superar a través de:

- $\quad$ educación ambiental dirigida a productores;

- acceso a información técnica y de mercados;

- mayor acercamiento de los aserríos con la producción primaria (a nivel de fincas);

- e implementación vía casas comerciales de la venta de semillas forestales certificadas. 
En cuanto al aprovechamiento, se identificaron barreras relacionadas al desconocimiento de la Ley y los procedimientos para aprovechar los árboles en fincas ganaderas, y del manejo forestal adecuado para fines del mercado. Como solución, además de fortalecer la capacidad operacional y presencia del INAFOR para lograr mayor dinamismo y reducir la ilegalidad, se planteó:

- Capacitación en la Ley Forestal y en manejo forestal.

- Revisar la Ley de Veda Forestal para hacerla más flexible para el aprovechamiento.

- Favorecer la regeneración natural para que pueda entrar en el esquema de incentivos, siempre y cuando exista un plan de manejo mínimo y en zonas críticas.

Para fomentar un programa nacional que agregue valor a los productos maderables a nivel de explotaciones agrosilvopastoriles, resulta fundamental el establecimiento de mayores sinergias entre los diferentes sectores que participan en la cadena forestal. También se indicó lo siguiente:

- Es importante aprovechar más la relación del INAFOR con las municipalidades.

- Se debe tener una mayor coordinación interinstitucional para disminuir costos de aprovechamiento y hacer un manejo sostenible, y explorar algunos proyectos pilotos de incentivos específicos a estos desarrollos.

- Esta cadena productiva se puede fomentar, al menos a nivel local, favoreciendo especies viables por zonas.

Asimismo, hubo gran interés en el fomento de la regulación y control de la fiscalidad y la participación ciudadana efectiva en el desarrollo de este tipo de actividades. Se hizo hincapié en evitar el tráfico de influencias como un mecanismo para fortalecer la gobernabilidad.

En cuanto al fortalecimiento de las capacidades instaladas para desarrollos forestales en fincas ganaderas, se resaltó la necesidad de impulsar tanto las escuelas técnicas rurales en manejo sostenible de recursos en fincas ganaderas como la creación de servicios empresariales de apoyo para el sector forestal. Esto debe redundar en capacidades para prestar servicios profesionales como la regencia forestal pagada por los productores.

Se propone un programa nacional de carácter descentralizado (alianza INAFOR - MAGFOR - alcaldías) para llevar adelante las tareas anteriormente expuestas. Sin embargo, la responsabilidad de impulsarlo recaería en organizaciones de productores. Por su parte, el Sistema Nacional Forestal (SNAF) debería de tener como prioridades la búsqueda de mercados nacionales y/o internacionales para productos forestales de fincas ganaderas certificadas (requiere NTON) y la capacitación en aspectos técnicos- productivos en función de mejorar el aprovechamiento técnico de la madera.

\section{Conclusiones}

- El Estado nicaragüense ha tenido dificultades para formular y ejecutar una política que fomente la actividad forestal como un componente atractivo para los finqueros ganaderos. La política sigue estando dirigida principalmente a los dueños de bosques 
y plantaciones forestales en un país donde la mayor proporción de madera y leña está distribuida entre miles de fincas que se dedican principalmente a la producción agropecuaria.

- Las políticas actuales no favorecen al establecimiento y adopción de buenas prácticas productivas y sostenibles en el sector silvoagropecuario, lo que favorece malas prácticas y la ilegalidad de las explotaciones forestales pequeñas. Se requieren reformas profundas con un enfoque multisectorial.

- La participación de las miles de fincas ganaderas en el aprovechamiento sostenible y aumento de los stocks forestales del país se ve limitada por una serie de barreras legales como las siguientes: a) las pequeñas fincas agropecuarias son consideradas poco importantes en la producción y por ende en la legislación forestal del país; b) los trámites burocráticos y altos costos de transaccion en que deben incurrir los pequeños y medianos propietarios de bosques -mayores a 10 ha- para solicitar permisos de aprovechamiento y c) para el aprovechamiento forestal en fincas mayores a 500 ha hay obligatoriedad de elaborar costosos estudios de impacto ambiental, elaborar el plan de manejo y pagar regencia.

- A nivel más local o municipal, existe un gran potencial para el aprovechamiento forestal en fincas ganaderas mediante un manejo técnico forestal mejor planificado y sostenible.

- La ilegalidad y el aprovechamiento no sostenible de los recursos forestales es favorecido por el poco conocimiento de parte de los pequeños y medianos finqueros ganaderos sobre la legislación forestal del país y sus implicaciones. Esto se suma a la falta de coordinación entre los actores institucionales, la alcaldía y el INAFOR, para el fomento de la actividad y otorgamiento de permisos de extracción.

- Aunque la legislación y la política forestal brindan algunos espacios e incentivos para el fomento e investigación agroforestal y silvopastoril en fincas, éstos se quedan cortos en comparación con las restricciones y cargas administrativas que se imponen al aprovechamiento.

- Los limitados espacios que la legislación y política forestales brindan para el aprovechamiento sostenible de los recursos arbóreos en fincas ganaderas no se han traducido ni siquiera en un involucramiento piloto de los miles de finqueros ganaderos.

- Los enfoques más conservacionistas siguen propugnando por medidas encaminadas a hacer más rígido el control de la madera. Con la entrada en vigencia de la nueva Ley de Veda Forestal, esta legislación se vuelve aún más restrictiva. Un enfoque político alternativo es el de incentivar a los finqueros a reducir la presión sobre el bosque mediante el establecimiento de más árboles en sus fincas. Esto se puede hacer mediante plantaciones forestales o sistemas agroforestales y silvopastoriles. Este último enfoque aún no está presente en la agenda gubernamental ni en la de muchos organismos que intervienen en el sector, siendo abordado de forma insuficiente en la política y legislación forestal vigente.

- Si no se replantea una política que esboce un modelo de desarrollo forestal que favorezca a los grupos rurales más vulnerables asentados en suelos degradados y/o con potencial forestal, la nueva Ley de Veda podría cerrar los pocos espacios positivos que les brinda la legislación forestal. 


\section{Recomendaciones}

- Difundir masivamente la Ley Forestal, su Reglamento y lo relacionado a los incentivos forestales para que los pequeños y medianos productores utilicen las ventanas que les favorecen en este marco legislativo.

- Desarrollar un instrumento legal específico - puede ser una Norma Técnica Obligatoria Nicaragüense (NTON) - para la certificación e incentivo de desarrollos silvícolas en fincas ganaderas.

- Discutir los alcances e implicaciones de la actual Ley de Veda Forestal con los actores involucrados y con un enfoque hacia un "cliente forestal" diverso y amplio y reflexionar mecanismos para evitar un mayor desestímulo a la actividad forestal.

- Mejorar la coordinación interinstitucional entre el ente regulador del recurso forestal (INAFOR), las municipalidades y los productores para eliminar los obstáculos derivados que frenan el desarrollo del aprovechamiento forestal sostenible en fincas ganaderas.

- Mejorar la gestión del conocimiento y la capacitación a instituciones relevantes y productores para lograr un mejor manejo forestal de las fincas: simplificación de procesos, asistencia técnica y capacitación.

- Fortalecer los procesos de desconcentración y descentralización del sector rural (MAGFOR, INAFOR, INTA) y de la gestión ambiental (MARENA). De esta forma se pueden acercar las herramientas e instrumentos sectoriales para una gestión silvoagropecuaria diversificada, generadora de mayores ingresos para la población rural, más competitiva y ambientalmente sostenible.

- Revisar con funcionarios del sector forestal del país si el objetivo de la Política Forestal (Decreto 50-2001) de "lograr el desarrollo sostenible del sector forestal, constituyéndose en una alternativa viable para elevar la calidad de vida de la población ligada al recurso y en un eje de desarrollo para la economía nacional" podría aceptar "el fomento, desarrollo y aprovechamiento forestal en fincas ganaderas" como uno de los lineamientos de trabajo para contribuir a revertir la problemática forestal del país.

- Promover una mayor organización entre los finqueros pequeños, medianos y grandes de cara a lograr encadenamientos productivos con los sectores transformadores nacionales, hacer más atractiva la producción forestal en las fincas y mejorar la competitividad y el desarrollo sostenible del sector.

\section{Notas}

* Artículo basado en los resultados del estudio del mismo nombre que realizara CATIE y NITLAPAN en el marco del proyecto regional "Desarrollo participativo de alternativas de uso sostenible de la tierra en áreas con pasturas degradadas en América Central", que ejecuta CATIE en Nicaragua, financiado por el Gobierno de Noruega.

Debido a problemas de suministro, en algunas zonas del país esto es una realidad.

2 El modelo relaciona vegetación original (máximo biodiversidad) contra cambio de uso de la tierra, intensidad de la producción agrícola, intensidad de la producción ganadera, producción forestal, incendios forestales y quemas, infraestructura vial y fragmentación del bosque.

3 Instancia superior de concertación social del sector forestal. Tiene participación en la formulación, seguimiento, control y aprobación de la política, la estrategia y demás normativas que se aprueben en materia forestal. 
4 Los aprovechamientos forestales en fincas muy pequeñas resultarán en serias consecuencias para los ecosistemas, por lo que "no se debe incentivar" estos desarrollos. Sin embargo, negar su existencia resulta en un vacío legal que más bien favorece este tipo de explotación forestal.

5 El desarrollo forestal en Chile y recientemente en Argentina, son evidencia de esta afirmación. En Chile comenzó con demandas de madera para construcción de viviendas; en Argentina hay una gran demanda de madera para cajas de fruta de exportación.

\section{Referencias bibliográficas}

BARAHONA, T. (1997). "La política forestal. El tiro por la culata”. En Envío Revista de la Universidad Centroamericana. No.185. Universidad centroamericana (UCA): Managua. (Disponible en www.envio.org.ni)

BARAHONA, T. (2002). "El bosque y la gente, pueden coexistir". En Nitlapan - CCAD MARENA - MNP - SNV. 2006. Informe Técnico. MACABIO 1. Mimeo.

ESQUIVEL. J. (2005). Efectos de la composición y el manejo de las pasturas sobre la |abundancia, riqueza, diversidad y composición de especies y plántulas de árboles y arbustos en potreros con ganadería activa en el municipio de Muy Muy, Matagalpa, Nicaragua. Tesis de Maestría. CATIE: Turrialba.

FAURBY, O. (2005). El sector forestal de Nicaragua. Una oportunidad desaprovechada para el desarrollo. IPADE: Managua.

GLOBAL WITNESS (2007). Monitoreo forestal independiente en Nicaragua. INAFOR - Global Witness: Managua.

INEC (INSTITUTO NICARAGUENSE DE ESTADISTICAS Y CENSOS) (2002). Censo Nacional Agropecuario. INEC: Managua.

LARSON, A. (2006). Políticas forestales nacionales y locales. Institucionalidad para la participación ciudadana. Fundacion Ford-Nitlapan: Managua

LARSON, A \& ZELEDÓN V. (2004). "Lo municipal y lo forestal. ¿Cómo, hacia donde, para quienes?” En Envío Revista de la Universidad Centroamericana. No 267. Universidad centroamericana (UCA): Managua. (Disponible en www.envio.org.ni)

MAGFOR; PROFOR \& INAFOR (2002). Valoración Forestal de Nicaragua. MAGFOR: Managua.

SEGURA, O. (1997). Falta título del capítulo. En CIFOR, CCAB-AP, FAO, GTZ, IICA, UICN, WRI. Políticas forestales en Centroamérica. Análisis de las restricciones para el desarrollo del sector forestal.

SERRATO, C. (2002). Instrumentos institucionales para el desarrollo de dueños de pequeñas tierras de vocación forestal. Informe legal de país. Banco Interamericano de Desarrollo (BID): Managua.

SZOTT, L; IBRAHIM, M \& BEER, J. (2000). The Hamburger Connection Hangover; Cattle, Pasture, Land Degradation and Alternative Land Use in Central America. CATIEDANIDA-GTZ: Turrialba.

VAN DER ZEE, J. (2007). Informe Técnico. Ordenamiento territorial del Municipio de Muy Muy. En fase de consulta. Matagalpa. Mimeo. 
Anexo 1. Marco de políticas, leyes y decretos del sector forestal consultados

\begin{tabular}{|c|c|c|c|c|}
\hline \multicolumn{5}{|c|}{ Políticas nacionales } \\
\hline Nombre & Objeto & Facilidad & Dificultad & Recomendación \\
\hline $\begin{array}{l}\text { Constitución de la } \\
\text { República } \\
\\
\text { Política de } \\
\text { Desarrollo } \\
\text { Forestal }\end{array}$ & $\begin{array}{l}\text { Protege los } \\
\text { derechos } \\
\text { fundamentales } \\
\\
\text { Desarrollo } \\
\text { sostenible del } \\
\text { sector forestal }\end{array}$ & $\begin{array}{l}\text { Protege derechos de } \\
\text { propiedad (los } \\
\text { comunales), la titularidad } \\
\text { pública de los RRNN, } \\
\text { derechos al desarrollo } \\
\text { suste ntable, reconoce el } \\
\text { papel delos municipios } \\
\text { en la gestión del recurso. } \\
\\
\text { Limita la "depredación" } \\
\text { del recurso }\end{array}$ & $\begin{array}{l}\text { Por su naturaleza es un } \\
\text { instrumento general. } \\
\text { Contiene contradicciones } \\
\text { a nivel del poder local, } \\
\text { especialmente en las } \\
\text { regiones autónomas en } \\
\text { materia de competencias } \\
\text { concurrentes entre } \\
\text { municipios y autoridades } \\
\text { originarias. } \\
\text { Es restrictiva en cuanto a } \\
\text { capacidad de exportación } \\
\text { y encarece el recu rso }\end{array}$ & $\begin{array}{l}\text { Se requiere } \\
\text { compatibilización en la } \\
\text { legislación específica. }\end{array}$ \\
\hline \multicolumn{5}{|c|}{ Leyes y decretos } \\
\hline Nombre & Objeto & Facilidad & Dificultad & Recomendación \\
\hline $\begin{array}{l}\text { Ley General de l } \\
\text { Medio Ambiente } \\
\text { y los Recursos } \\
\text { Naturales (Ley } \\
217 \text { - 1996) }\end{array}$ & $\begin{array}{l}\text { Crea y regula el } \\
\text { sector medio } \\
\text { ambiente y define } \\
\text { sus temas } \\
\text { centrales en } \\
\text { materia de ámbitos } \\
\text { temáticos. }\end{array}$ & $\begin{array}{l}\text { Declara queds recursos } \\
\text { naturales son parte del } \\
\text { patrimonio nacional, } \\
\text { establece derechos de } \\
\text { aprovechamiento, } \\
\text { concesiones, permisos, } \\
\text { licencias o cuotas; brinda } \\
\text { las bases para un sistema } \\
\text { de incentivos ambientales, } \\
\text { exonera del pago del IBI } \\
\text { por conservación de los } \\
\text { suelos y de la } \\
\text { biodiversidad. }\end{array}$ & $\begin{array}{l}\text { El ámbito de competencia } \\
\text { de laLey en materia } \\
\text { forestal está restringido a } \\
\text { áreas bajo régimen de } \\
\text { protección. } \\
\text { Incentivo fiscal "castiga" } \\
\text { las recaudaciones } \\
\text { municipales. }\end{array}$ & $\begin{array}{l}\text { Desarrollar sistemas de } \\
\text { incentivos municipales } \\
\text { fiscales retributivos en } \\
\text { materia de desarrollo } \\
\text { económico y protección } \\
\text { ambiental. }\end{array}$ \\
\hline $\begin{array}{l}\text { Ley de } \\
\text { Organización, } \\
\text { Competencia y } \\
\text { Procedimientos } \\
\text { del Poder } \\
\text { Ejecutivo (Ley } \\
290 \text { - 1998). } \\
\\
\text { Ley de } \\
\text { Municipios (Ley } \\
\text { No. 40) y sus } \\
\text { reformas (261) }\end{array}$ & $\begin{array}{l}\text { Crea al MIFIC, el } \\
\text { MAGFOR, el } \\
\text { INAFOR y el } \\
\text { MARENA }\end{array}$ & $\begin{array}{l}\text { Establece un esquema de } \\
\text { gestión de política y } \\
\text { administración de } \\
\text { derechos, permisos y } \\
\text { concesiones para recursos } \\
\text { forestales protegidos y no } \\
\text { protegidos. } \\
\\
\text { Los gobiernos } \\
\text { municipales tienen } \\
\text { competencia en todas las } \\
\text { materias que incidan en el } \\
\text { desarrollo } \\
\text { socioeconómico y la } \\
\text { conservación del } \\
\text { ambiente y los recursos } \\
\text { naturales de su territorio, } \\
\text { y el ordenamiento de su } \\
\text { territorio a través del } \\
\text { Sistema de Planificación } \\
\text { Municipal. }\end{array}$ & $\begin{array}{l}\text { Fragmenta las decisiones } \\
\text { sobre acceso, uso y } \\
\text { aprovechamiento de los } \\
\text { recursos forestales. } \\
\text { Dada la poca capacidad } \\
\text { del INAFOR de } \\
\text { dislocación en el } \\
\text { territoriose dificulta el } \\
\text { ordenamiento del sector. } \\
\text { Las atribuciones citadas } \\
\text { son restringidas a simple } \\
\text { opinión Las concesiones } \\
\text { dependen más bien del } \\
\text { MIFIC (ADFOREST); se } \\
\text { gener a así, un conflicto de } \\
\text { competencias que no } \\
\text { favorece un manejo } \\
\text { forestal coherente y } \\
\text { armónico. }\end{array}$ & $\begin{array}{l}\text { Fortalecer las capacidades } \\
\text { locales en un ámbito } \\
\text { descentralizado en } \\
\text { función de una } \\
\text { administración más } \\
\text { consiłente y coherente de } \\
\text { los recursos naturales }\end{array}$ \\
\hline
\end{tabular}




\begin{tabular}{|c|c|c|c|c|}
\hline $\begin{array}{l}\text { Ley de Desarrollo } \\
\text { y Fomento del } \\
\text { Sector Forestal } \\
\text { (Ley } 462-2003 \text { ). }\end{array}$ & \begin{tabular}{|l|} 
Establece el \\
régimen legal para \\
la conservación, \\
fomento y \\
desarrollo \\
sostenible del \\
sector forestal \\
\end{tabular} & $\begin{array}{l}\text { Integra un marco para el } \\
\text { manejo del bosque } \\
\text { natural, el fomento de las } \\
\text { plantaciones, la } \\
\text { protección, conservación } \\
\text { y restauración de áreas } \\
\text { forestales Hace partícipes } \\
\text { a los gobiernos } \\
\text { regionales, municipales y } \\
\text { a la sociedad civil, en la } \\
\text { gestión en un contexto } \\
\text { descentralizado y } \\
\text { desconcentrado. } \\
\text { Reconoce los múltiples } \\
\text { beneficios en bienes y } \\
\text { servicios producidos por } \\
\text { los bosques. }\end{array}$ & \begin{tabular}{|l} 
La poca capacidad \\
ejecutiva y de operaciones \\
del INAFOR limita \\
sensiblemente su \\
aplicación en el campo. \\
Al ser una Ley forestal, \\
los asuntos forestales en \\
fincas ganaderas no son \\
tratados con claridad en el \\
cuerpo de la Ley.
\end{tabular} & $\begin{array}{l}\text { Fortalecimiento del } \\
\text { INAFOR, fomento a } \\
\text { convenios con } \\
\text { municipios. } \\
\text { Desarrollar NTON } \\
\text { relacionada a } \\
\text { aprovechamiento y } \\
\text { fomento forestal en } \\
\text { plataformas ganaderas. }\end{array}$ \\
\hline $\begin{array}{l}\text { Reglamento de la } \\
\text { Ley Forestal: } \\
\text { Decreto 73-2003. }\end{array}$ & \begin{tabular}{|l|} 
Crea el SNAF,el \\
CONAFOR y el \\
ONRF en el \\
INAFOR, Sistema \\
de Regencia, los \\
Convenios con \\
Municipios y \\
regula el régimen \\
de \\
aprovechamiento \\
(y pagos), \\
transporte, \\
almacenamientos, \\
transformación y \\
conservacióny \\
manejo de plagas \\
del recurso
\end{tabular} & $\begin{array}{l}\text { Genera un esquema de } \\
\text { participación para la } \\
\text { gestión forestal a la vez } \\
\text { que permite el } \\
\text { establecimiento de } \\
\text { convenios para la } \\
\text { implantación de un } \\
\text { mecanismo } \\
\text { descentralizado a nivel } \\
\text { municipal para el manejo, } \\
\text { aprovechamiento y } \\
\text { conservación del recurso } \\
\text { forestal. }\end{array}$ & $\begin{array}{l}\text { Tradición centralista de la } \\
\text { política nacional } \\
\text { Obstaculiza el desarrollo } \\
\text { de convenios con } \\
\text { gobiernos municipales. } \\
\text { El regente forestal queda } \\
\text { poco protegido, lo que lo } \\
\text { hace vulnerable a } \\
\text { presiones de empresas. }\end{array}$ & $\begin{array}{l}\text { Incentivo a prácticas de } \\
\text { descentralización a través } \\
\text { de mayor presupuesto } \\
\text { operacional al INAFOR, } \\
\text { desarrollo de experiencias } \\
\text { piloto y sistematización } \\
\text { para su escalamiento. } \\
\text { Revisar la situación de } \\
\text { vulnerabilidad del regente } \\
\text { forestal. }\end{array}$ \\
\hline $\begin{array}{l}\text { Disposiciones } \\
\text { para el manejo } \\
\text { sostenible de los } \\
\text { bosques } \\
\text { tropicales } \\
\text { (Resolución } \\
\text { administrativa } \\
\text { No. 35-2004) }\end{array}$ & \begin{tabular}{|l|} 
Establece \\
disposiciones \\
administrativas \\
para el manejo \\
sostenible de los \\
bosques naturales \\
tropicales, \\
latifoliados, \\
coníferas y \\
plantaciones \\
forestales
\end{tabular} & $\begin{array}{l}\text { Define los requisitos y } \\
\text { procedimientos para el } \\
\text { aprovechamiento en } \\
\text { fincas agrosilvopastoriles. }\end{array}$ & $\begin{array}{l}\text { A la Delegación del } \\
\text { INAFOR le corresponde } \\
\text { la inspección técnica } \\
\text { gratuita y emitir } \\
\text { una guía de transporte } \\
\text { simplificada } \\
\text { sin costo alguno. Pero se } \\
\text { dificulta por ladebilidad } \\
\text { de personal y cobertura } \\
\text { del INAFOR. }\end{array}$ & $\begin{array}{l}\text { Promover convenios con } \\
\text { gobiernos locales para la } \\
\text { simplificación de } \\
\text { procesos e instrumentos } \\
\text { económicos. }\end{array}$ \\
\hline $\begin{array}{l}\text { Ley de } \\
\text { Participación } \\
\text { Ciudadana (Ley } \\
475 \text { ) }\end{array}$ & $\begin{array}{l}\text { Define } \\
\text { instrumentos de } \\
\text { participación en } \\
\text { las decisiones } \\
\text { políticas a varios } \\
\text { niveles: nacional, } \\
\text { regional, } \\
\text { departamental y } \\
\text { local. }\end{array}$ & $\begin{array}{l}\text { Esta Ley refuerza las } \\
\text { instancias y mecanismos } \\
\text { de participación } \\
\text { establecidos en la Ley de } \\
\text { Municipios, establece } \\
\text { criterios para la } \\
\text { promoción de resolución } \\
\text { y ordenanzas municipales, } \\
\text { exige consultas sobre } \\
\text { asuntos de importancia } \\
\text { (RRHH) y establece } \\
\text { mecanismos de reclamo. }\end{array}$ & $\begin{array}{l}\text { Puedemejorar la } \\
\text { rendición de cuentas por } \\
\text { parte del gobierno a todos } \\
\text { los niveles y la } \\
\text { participación directa en la } \\
\text { gestión de la política, sin } \\
\text { embargo, la creación de } \\
\text { muchas instancias de } \\
\text { concertación tienden a } \\
\text { diluir su poder efectivo. }\end{array}$ & \\
\hline
\end{tabular}




\begin{tabular}{|c|c|c|c|c|}
\hline $\begin{array}{l}\text { Reglamento de } \\
\text { Incentios } \\
\text { Forestales: } \\
\text { Decreto } 104- \\
2005 .\end{array}$ & $\begin{array}{l}\text { Reglamenta en } \\
\text { Cap. IV de Ley } \\
462 .\end{array}$ & $\begin{array}{l}\text { Reconoce actividades de } \\
\text { atracción de inversiones } \\
\text { y de ampliación de } \\
\text { disponibilidad de materia } \\
\text { prima en el sector } \\
\text { forestal }\end{array}$ & $\begin{array}{l}\text { Demasiado general y no } \\
\text { reglamentado claramente. }\end{array}$ & $\begin{array}{l}\text { Desarrollarløomo } \\
\text { reforma o en el marco de } \\
\text { una NTON. }\end{array}$ \\
\hline $\begin{array}{l}\text { Ley de Delitos } \\
\text { Ambientales (Ley } \\
\text { 559-2005) }\end{array}$ & \begin{tabular}{|l|} 
Tipifica el delito \\
contra \\
el medio ambiente \\
y los recursos \\
naturales, las \\
acciones u \\
omisiones \\
relativas a la \\
conservación, \\
protección, \\
manejo, defensa y \\
mejoramiento del \\
ambiente \\
Establecela \\
responsabilidad \\
civil por daños y \\
perjuicios con \\
responsabilidad \\
comprobada.
\end{tabular} & $\begin{array}{l}\text { Penaliza el daño } \\
\text { ambiental que "sale" de lo } \\
\text { meramente civil y } \\
\text { administrativo "hacia" lo } \\
\text { penal, fortaleciendo la } \\
\text { provisión de justicia por } \\
\text { daño. }\end{array}$ & $\begin{array}{l}\text { Requiere de una } \\
\text { Procuraduría fuerte que } \\
\text { no cuenta ni con el } \\
\text { personal nicon el } \\
\text { presupuesto suficiente } \\
\text { para dar cobertura. } \\
\text { Mal comunicada }\end{array}$ & $\begin{array}{l}\text { Fortalecer el sistema de } \\
\text { justicia y mejorar la } \\
\text { comunicación de la Ley. }\end{array}$ \\
\hline $\begin{array}{l}\text { Ley de Veda } \\
\text { Forestal (Ley } \\
585-2006)\end{array}$ & $\begin{array}{l}\text { Establece veda de } \\
\text { corte, } \\
\text { aprovechamiento } \\
\text { y comercialización } \\
\text { de caoba, cedro, } \\
\text { pochote, pino, } \\
\text { mangle y ceibo } \\
\text { por 10años. } \\
\text { Prohibe la } \\
\text { exportación de } \\
\text { madera de bosque } \\
\text { natural sin planes } \\
\text { de manejo en } \\
\text { áreas protegidas } \\
\text { Estipulaotras } \\
\text { restricciones en } \\
\text { áreas de } \\
\text { amortiguamiento }\end{array}$ & $\begin{array}{l}\text { Genera un mecanismo de } \\
\text { control para los } \\
\text { aprovechamientos ilegale } \\
\text { o irregulares. } \\
\text { Promueve, por defecto, la } \\
\text { legalidad y los eslabones } \\
\text { de segunda y tercera } \\
\text { transformación }\end{array}$ & $\begin{array}{l}\text { Encarece las especies } \\
\text { vedadas, lo que incentiva } \\
\text { el tráfico ilegal. } \\
\text { No se asocia a un } \\
\text { mecanśmo de incentivo } \\
\text { para la reconversión e } \\
\text { innovación en el sector. } \\
\\
\text { Mal comunicada }\end{array}$ & $\begin{array}{l}\text { Fortalecer el fomento a la } \\
\text { reconversión e innovación } \\
\text { en el sector a través de } \\
\text { incentivos. } \\
\text { Comunicar más la Ley. }\end{array}$ \\
\hline
\end{tabular}




\section{Anexo 2. Normas del INAFOR para el aprovechamiento forestal con áreas boscosas}

1. Para el aprovechamiento forestal en fincas con áreas boscosas menores de 10 ha:

- Plan de reposición forestal (guía metodológica del INAFOR).

- Designación del regente.

- Título de dominio de la propiedad o documento posesorio.

- Cesión de derecho en original o copia autenticada por Notario Público en el caso de ceder los derechos de aprovechamiento.

- Autorización de la Dirección General de Áreas Protegidas del MARENA cuando la propiedad se encuentra dentro de éstas.

2. Para el aprovechamiento forestal en fincas con áreas boscosas mayores de 10 ha:

- Plan mínimo de manejo forestal, hasta 50 ha (guía metodológica del INAFOR).

- Designación del regente.

- Título de dominio de la propiedad o documento posesorio.

- Cesión de derecho en original o copia autenticada en el caso de ceder los derechos de aprovechamiento.

- Cuando la propiedad se encuentra en un área protegida, autorización de la Dirección General de Áreas Protegidas del MARENA.

3. Para el manejo forestal en bosques naturales (áreas de bosque no fragmentado):

- Solicitud por escrito de aprobación del permiso de aprovechamiento.

- Plan general de manejo forestal con sus respectivos planes operativos anuales (guía metodológica del INAFOR).

- Designación del regente.

- Título de dominio de la propiedad o documento posesorio.

- Cesión de derecho en original o copia autenticada en el caso de ceder los derechos de aprovechamiento.

- Autorización de la Dirección General de Áreas Protegidas del MARENA cuando la propiedad se encuentra dentro de ellas.

El Artículo 48 establece que los permisos de aprovechamiento forestal serán otorgados una vez cumplidos los requisitos establecidos en el artículo anterior, en los siguientes períodos:

- Para el aprovechamiento forestal en fincas con áreas boscosas menores de 10 has, 1 día hábil.

- Para el aprovechamiento forestal en fincas con áreas boscosas mayores de 10 has, 15 días hábiles.

- Para el manejo forestal en bosques naturales (no fragmentado), 30 días hábiles.

El Artículo 52 indica que el aprovechamiento no comercial para uso propio del dueño de la finca y exclusivo de la misma no requerirá de permiso forestal y el Artículo 57 establece que el INAFOR emitirá permisos de aprovechamiento de leña en un solo trámite cuando se trate de los residuos resultantes de las actividades productivas en fincas agrosilvopastoriles. 